PROJECT REPORT

\title{
Rediscovering the Tradition of Painted Caribou Belongings in Eeyou Istchee: A Community-Based and Community-Led Research Project
}

\author{
Aanischaaukamikw Cree Cultural Institute \\ Margaret Orr \\ Aanischaaukamikw Cree Cultural Institute
}

Natasia Mukash

Aanischaaukamikw Cree Cultural Institute

Paula Menarick

Aanischaaukamikw Cree Cultural Institute

\begin{abstract}
One of the core programming goals at Aanischaaukamikw Cree Cultural Institute is to rediscover, relearn, and reintroduce the traditions of our historic belongings through the display, study, and research of belongings currently cared for by museums outside our region. In 2017, we received funding from the Canada Council of the Arts for a multi-year research and knowledge creation project, "Rediscovering the Tradition of Painted Caribou Coats in Eeyou Istchee." Our project brought Eeyou knowledge together with surviving examples of painted caribou coats and accessories from the eighteenth and nineteenth centuries usually referred to, and classified as, "Naskapi" by museums and "experts" outside our region.
\end{abstract}

Keywords: Decolonization; self-determination; Eeyou Istchee; community-based research; painted caribou coats

\section{Introduction}

Aanischaaukamikw Cree Cultural Institute (Figures 1 and 2) opened in 2011 after many decades of planning and fundraising. For decades, Elders in Eeyou Istchee had wanted somewhere to preserve and strengthen "the ways." Part of our cultural programming involves research into historic collections extracted from our territory in the last centuries. This research allows us to rediscover, relearn, and reintroduce the traditions of our ancestors that are revealed in belongings currently cared for, or incarcerated by, ${ }^{1}$ museums and other memory institutions. This project report shares our process and some of our research outcomes from a community-based research project partially funded by the Canada Council of the Arts, "Rediscovering the Tradition of Painted Caribou Coats in Eeyou Istchee." The goals of this project were to bring Eeyouch ${ }^{2}$

\footnotetext{
${ }^{1}$ Using terminology like incarceration to describe belongings held in museums is becoming more frequent, a term which presents an alternative view to museums as "places of care and preservation" to places of detention, removal, and imposed authority, as explained by Dylan Robinson (2020): "Instead, what exists behind the glass goes by other names; they have life, they are living beings, or they are ancestors. Indigenous people have intimate kinship with these beings. As such, the fact that they are 'held' behind glass, in drawers, in storage might be understood in terms of containment and confinement of life. Encountering 'loved ones' behind glass, in drawers, and in storage puts into question the ways in which museological standards of 'preservation' and 'conservation' might instead by understood as containment or even incarceration" (87).

${ }^{2}$ Eeyou (Eeyou/ lyiyiw, Eenou/ Iyiniw) means "the people" in our dialects of liyiyiumuwin (the Cree language). Eeyouch is the plural form of this word. Cree is a language used across Canada, with many dialects, and is the descriptive term that Eeyou refer to themselves by, though our name for ourselves is Eeyou in the coastal area and Eenou in the inland communities. Eeyou Istchee means "the people of the land" and refers to our self-governing territory that spans $5,271 \mathrm{~km}^{2}(2,035 \mathrm{sq}$. mi.), though our original territory prior to colonisation spanned 450,000 km² (170,000 sq. mi.) (Wikipedia 2020). For this report we will use Eeyou and Cree interchangeably, but we are only referring to our own region, not the entirety of the area where all dialects of Cree are spoken.
} 


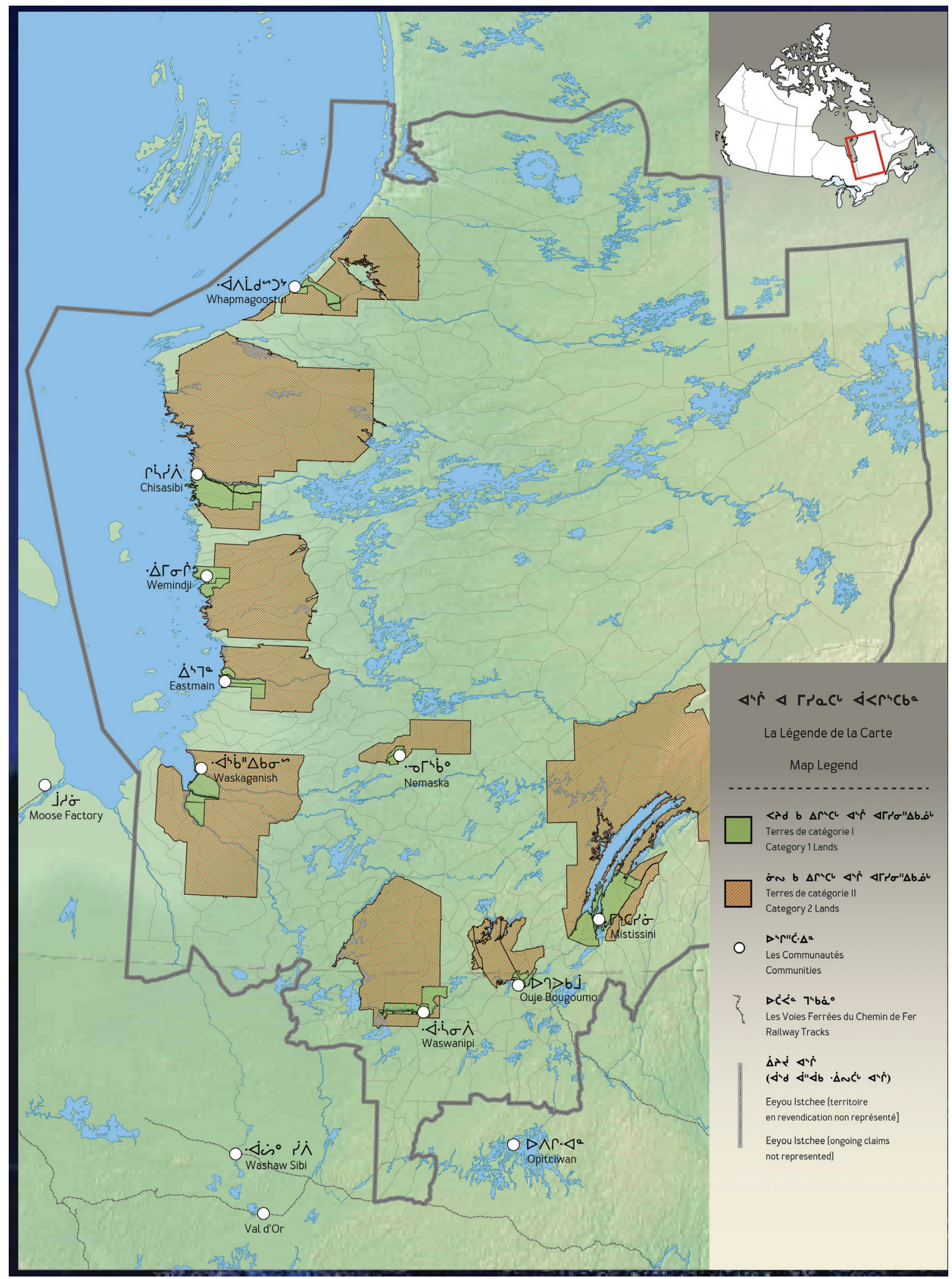

Figure 1: Map of Eeyou Istchee. Image courtesy of Cree Nation Government.

knowledge together with surviving examples of painted caribou coats and accessories created and worn in the eighteenth and nineteenth centuries that are usually referred to, and classified as, "Naskapi" by museums and "experts" outside our region. We relate to these belongings as Ancestors, with their own spirit and energy or life force. ${ }^{3}$ Our research found that without any records naming the makers or owners of these

\footnotetext{
${ }^{3}$ In the editorial process it was pointed out that we have capitalised some uses of Ancestors and Caribou and not others. We resisted the grammatical rules of making this consistent. This paper draws together writing from different people and we have left the choices of capitals as they were originally written because this was what made sense at the time the words were typed. This resists what Peter Cole refers to as
} 


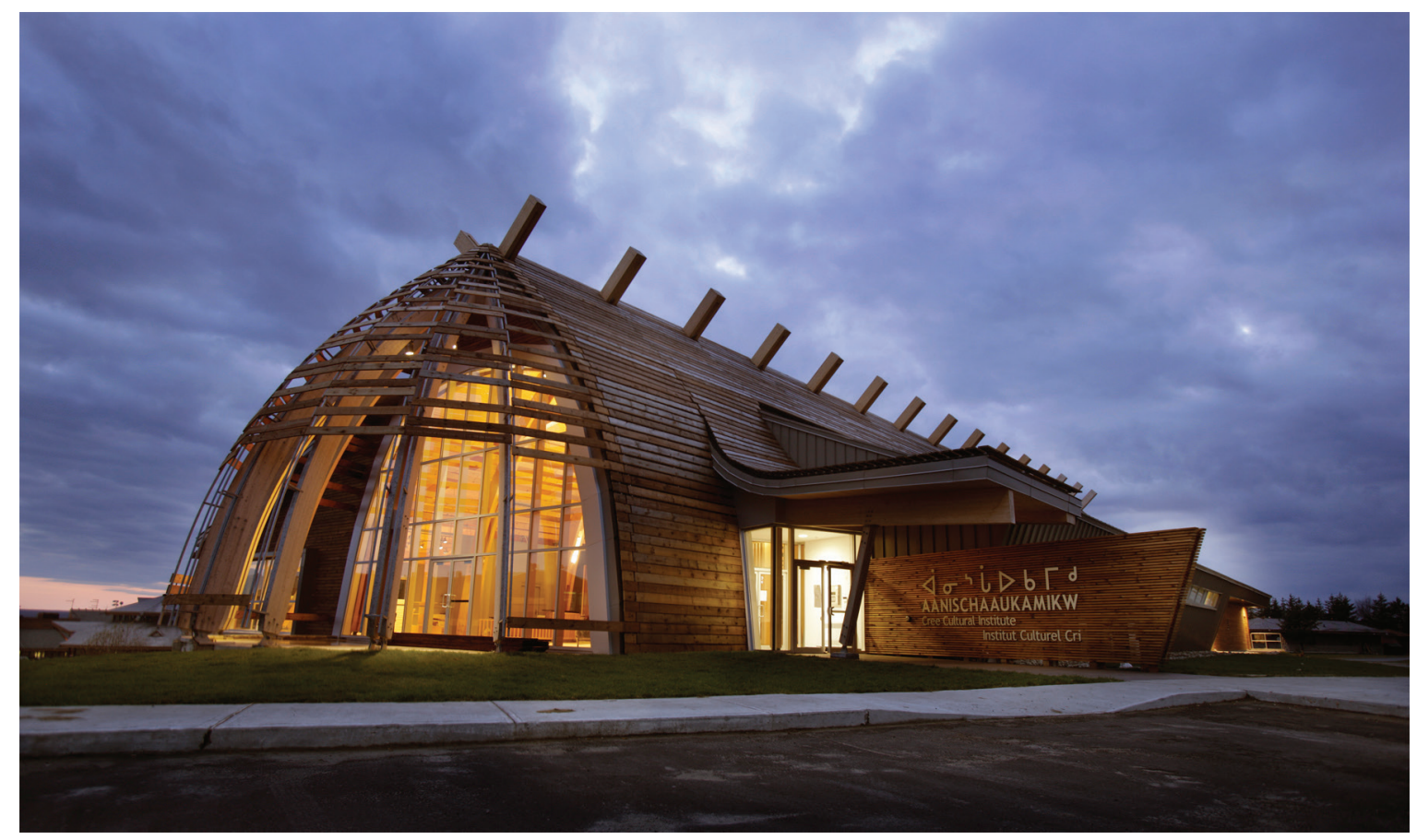

Figure 2: Aanischaaukamikw Cree Cultural Institute, 2012. Photo by Mitch Linet.

belongings, nor their ancestry or community lineages, the precise regional origins of these coats can never definitely be known, but our community researchers connected with our ancestors' belongings in ways that cannot easily be described in words on a page.

\section{Overview of Our Project}

The Caribou is a highly respected animal, as the Caribou carries everything someone would need to survive off the land. The caribou not only give themselves for us to nourish our bodies through their flesh but give us gifts to use as well. Every part of the caribou is used to make objects; nothing is wasted. For example, the caribou skins are turned into hide to sew moccasins, coats, and mittens; the caribou bones and antlers are carved into working tools for preparing the hide; the caribou muscles (tendons/fascia) are dried and used as sinew for sewing; and so on. With all that the caribou provides for the people, in return we honour the Caribou in many ways, such as painting, beading, embroidering, and quill working hides (our clothing), as beautifully as we can, to show the Caribou respect and honour.

Our research was led by Natasia Mukash, an artist/curator from Whapmagoostui Cree Nation; Margaret Orr, a multimedia artist/curator from Chisasibi Cree Nation; and Paula Menarick, an artist/ curator also from Chisasibi who has lived for many years in and around Ouje-Bougoumou Cree Nation. Many other community-based researchers, including Elders, youth, and wisdom/knowledge keepers, were part of our project.

\footnotetext{
ways of linearly encoding a western vision of the world

ways of encrypting experience so that little by little we are all molded into believing unthinkingly that there are beginnings middles ends believing that experience can be diagrammed graphed morphed this

the idea of capital versus small letters as being reflections of the world is a way of "class"ifying words caste-ing them and those who use them differentially it is a way of playing with value and with naming some words (we are to assume) are common some proper and because I do not see any noun as being un"common" or im"proper" and rather than using caste nomenclature orthographic diversion in the practice of capital and small letters rather than being equitable and capitalizing them all I capitalize only the ones which ask to be capitalized by which I mean I am writ the things which become words "write" me retroactively and in so doing make the choice themselves as to how they prefer to be and if at all on paper (Cole 2002, 449)
} 
In our community research, we applied the OCAP principles of Ownership, Control, Access, and Possession (First Nations Information Governance Centre 2020), and we focused research on relationships with each other, the land, and experience-based knowledge, defined by Yellowknives Dene First Nation scholar Glen Sean Coulthard $(2014,13)$ as "grounded normativity":

I call this place-based foundation of Indigenous decolonial thought and practice grounded normativity, by which I mean the modalities of Indigenous land-connected practices and longstanding experiential knowledge that inform and structure our ethical engagements with the world and our relationships with human and nonhuman others over time.

For our project, we interpreted this concept as letting what felt normal to our Eeyouch ways lead the process. This meant that our project followed an emergent process. Despite having to provide a detailed project plan in our initial grant application to Canada Council for the Arts, we adapted and revised the project timeline to reflect the availability of the community researchers and other project requirements as it progressed. The Canada Council for the Arts was accepting and understanding of our project revision as it moved forward, which felt empowering and made us view our project plan as evolving rather than a structure that had to be strictly followed.

The first months of our project focused on researching external knowledge that has been published about painted caribou coats and discussing this information, and the project in general, with Elders in both Whapmagoostui and Chisasibi. These communities have strong traditions of caribou hunting and material culture related to caribou ceremonies. ${ }^{4}$ The Elders consulted were strongly opposed to any reliance on external theories or interpretations of ceremonial aspects of caribou knowledge presented by non-Cree individuals, and they stated that individual designs should not be "interpreted" as they are personal and specific to each maker and the person the belongings are created for.

One of the earliest findings from speaking to Elders and knowledge keepers was that we should be researching entire outfits, not just the coats. The complete outfit would have had mittens, leggings, moccasins, and accessories like bags and pouches. These outfits, not just the coats, are important for us because there are so many aspects of our lengthy ancestral artistic practices that went into making these belongings, from the acquisition and fixing of the caribou hides to the creative patterns and designs that we still use today in decorating clothing and possessions. The colonisation of our territory in the last four hundred years means we have been impacted by attempted genocide, residential school removals, and having our ceremonies declared "illegal." ${ }^{5}$ Historical belongings of our ancestors are important to us today because we can use them to demonstrate the ongoing strength of our traditions, land-based teachings, and language.

Our research, based on knowledge shared by Elders in Whapmagoostui and Chisasibi, confirmed that there is a tradition of painted coats in the Eeyou Istchee region, something that outside "experts" and even some Eeyouch people associated only with our Naskapi neighbours. As further proof, the Cree Nation Government's toponymist recorded that David Bosum, an Elder from Ouje-Bougoumou, has a location on

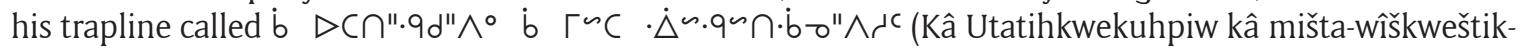
wânehpisut), which translates in English as "Caribou Coat wears a large headscarf," demonstrating the potential of ancestral knowledge held in place name research. ${ }^{6}$

Our communities value these painted caribou outfits because they are a direct connection to the knowledge held by our ancestors and the land. We know these outfits were used for ceremonial purposes in relation to the annual caribou hunt. It is possible that they were also worn for hunting, as this would follow our practice of wearing beautifully decorated clothing and accessories to honour the animals who give themselves to us while we hunt, and to carry the energy of the ceremony into the hunt. This is still done by our hunters today to honour the person who made the clothing and accessories and the spirits of the animals.

These coats have generally come to be referred to as "Naskapi coats" by external experts over the years. The locations (when known) from which coats were extracted may very well be in Naskapi, Cree, Innu, or Montagnais regions today, but this does not take account of the fact that the current "divisions" for community and "tribal" groupings do not reflect overlapping territories, travelling that was undertaken by

\footnotetext{
${ }^{4}$ For example, the late Emily Masty's lifelong project of gathering stories from Elders in Whapmagoostui Cree Nation was published in Mind's Eye: Stories from Whapmagoostui (2013). Some of the stories that include caribou are "Kâwâchikâtât" and "Pikutiskwâu," told by Peter Sandy and Noah Mamianskum; "The Boy Who Heard Sounds of Joyful Dancing," told by Matthew George; "Dreaming of Caribou," told by Rupert George and Noah Mamianskum; "So Much Food It Scared Him," told by Ronnie Sheshamush; "Hunting the Barren Grounds Caribou," told by Hannah Natachequan; "The Old Lady's Caribou," told by Sam Atchynia; "Caribou Mountain," told by John Kawapit; and "The Unhappy Caribou," told by Andrew Natachequan.

${ }^{5}$ For more on the unsuccessful attempts to repress Indigenous culture through colonial legislation like the Indian Act, please see George Manuel and Michael Posluns, The Fourth World: An Indian Reality ([1974] 2019).

${ }^{6}$ Sometimes the mountain is also called kâ mišta-wîškweštikwânehpisut (wears a large headscarf).
} 
community members, or intermarriages or other cultural exchanges that frequently took place (and still take place today). Many of these coats were extracted from our territory, which originally spanned 450,000 $\mathrm{km}^{2}$ and overlapped with that of our neighbours.

It is important for museums today to understand all of the confusion about the term "Naskapi" since it can mistakenly be used exclusively rather than expansively in understanding regional ancestries, and what has been called Naskapi by anthropologists and collectors is vastly different to how we understand the term today. ${ }^{7}$ Unless there is accurate documentation stating that the maker or wearer of the coat was from a Naskapi community, these coats should not be referred to as Naskapi coats because this term is unnecessarily exclusive. Like many belongings extracted from Indigenous Nations, the terms of reference need to be redefined in decolonizing processes led by Indigenous experts, which will take time and resources. Our research focuses on our own understandings of our cultural collections, using our own authority to interpret our own histories. Our right to self-curate our own culture, past and present, is guaranteed under the United Nations Declaration for the Rights of Indigenous Peoples (2007).

\section{Community Resources and Project Activities An Overview of Our Activities}

The project activities listed here demonstrate how we decided to undertake research into our historical belongings in a contemporary setting, using our community resources and knowledge.

Our project started with extensive research to evaluate external publications and museum holdings, and we consulted with Elders to evaluate the theories and opinions held by external "experts." We created a project Facebook page as one method of sharing and gathering community content. We also held community consultations to gather community knowledge from local experts. In 2018 and 2019, we undertook two research trips with Elders, knowledge keepers, master craftspeople, youth representatives, and culture teachers. On one trip, we travelled to view painted caribou coats and other belongings in Gatineau at the Canadian Museum of History and in Ottawa at the National Gallery of Canada. ${ }^{8}$ The other trip was to the Royal Ontario Museum in Toronto.

In addition, we held artist residencies at Aanischaaukamikw to activate the knowledge that was being shared during this project and to demonstrate how our contemporary artists still draw inspiration from the landscapes in Eeyou Istchee, in line with the artistic creations of our ancestors expressed on their belongings. These residencies featured two Eeyou artists, Tim Whiskeychan of Waskaganish Cree Nation and Margaret Orr of Chisasibi Cree Nation. Margaret, as one of our project researchers, included elements of creation and inspiration from the historic caribou belongings in a second series of artistic workshops held in Ouje-Bougoumou, Mistissini, Eastmain, Chisasibi, and Whapmagoostui. ${ }^{9}$ In 2021 we plan to feature an exhibition of historic and contemporary painted caribou hide belongings at Aanischaaukamikw to showcase new creations from the project alongside historic belongings in our collections, including some that are on loan from other museums.

\section{Reflections on Our Trip to the Royal Ontario Museum}

In 2019, a group of Elders and knowledge keepers travelled from Eeyou Istchee to the Royal Ontario Museum. This trip followed a week-long workshop at Aanischaaukamikw, where we looked at the historic caribou belongings in our collections and made contemporary creations inspired by these works. Members of the research group had travelled from Chisasibi and Whapmagoostui for the initial workshops. We travelled by air from Chibougamau airport to Montreal, then stayed overnight in Montreal near the airport. Some of the Elders travelled by plane from Montreal to Billy Bishop airport in Toronto, while the rest of the group took the VIA train from Dorval to Toronto Union Station. In Toronto, we stayed within walking distance of

\footnotetext{
${ }^{7}$ José Mailhot's (1986) work includes the multiple spellings of Naskapi in different time periods and referring to people in multiple geographic locations, from the Atlantic coast to James Bay: Nashkopy (393), Nashcoppe (395); Nescaupick (395); Naskapit (398); Nascapis (399); Nacopie (403); Naskopie (404); Naskapee (404); Nascaupees (405); Nascapee (405). See Mailhot for a discussion of the wider language grouping of Algonquian or Algonkian, an all-encompassing term that is also used in some museum documentation. See also Bishop and Brousseau (2016) for a discussion of Naskapi, Eeyou, and our other regional neighbouring Nations.

${ }^{8}$ Paula Menarick, Laura Phillips, and Natasia Mukash had been to see the painted coat at the National Gallery of Canada in December 2015, before it went on display in the 2017 Our Masterpieces, Our Stories galleries. The National Gallery was willing to lend this coat to Aanischaaukamikw in advance of its display, but we were not able to complete the negotiations in the time frame required. Visiting the coat in storage with Greg Hill, Audain Senior Curator of Indigenous Art, to examine it in detail and take photographs was a wonderful opportunity. When we returned with the group in June 2018, the coat was on display, but we were invited to view it in the gallery prior to their public opening times, which meant that the case could be opened and we could view the coat without a glass barrier between us. We thank the National Gallery for these generous accommodations for our visits.

${ }^{9}$ We had a workshop planned at the hotel in Montreal where the patients and families stay when they are flown for specialist treatment that the Cree Health Board cannot provide in the region. However, this had to be postponed with the outbreak of the COVID-19 pandemic in March 2020. We hope to reschedule this workshop and hold additional workshops in some of the other Cree communities and possibly in some urban centres where Eeyouch live.
} 
the Royal Ontario Museum and spent three days in the secure storage areas looking at belongings from our region. Some of the Elders were in their eighties, so we built in a lot of rest time so that they would not be too exhausted from two days of travelling. Prior to this trip we had been sent reports of the ROM collections, from which we were able to select the belongings that most interested us for this trip.

Paula Menarick (2019) shared these details about our trip to the Royal Ontario Museum in August 2019:

There are many caribou teachings that were shared throughout both weeks of the research project ${ }^{10}$ and everyone had a chance to share their community teachings about the Caribou. In this research project we had participants from Whapmagoostui, Schefferville (Naskapi) and Chisasibi. Teachings were rich and touched on many other topics because they are all intertwined and connected in the Cree way of Life. All participants pulled more and more puzzle pieces together to further understand the teachings of our ancestors....

The participants approached this workshop with great respect and interest because of how we were all taught growing up to honour and respect the caribou. We were very excited to visit many of the caribou hide painted objects. As the caribou hide objects were presented to the group many of us felt an instant connection to our ancestors and culture especially through being able to touch and handle the objects. ${ }^{11}$ To us these are not only objects but living objects. We all felt very fortunate and honoured to be able to connect with our ancestors this way.

\section{Knowledge Shared During Artist Workshops, January-February 2020}

In planning the community workshops, Margaret used "practice-based research" methodologies, defined by Linda Candy and Ernest Edmonds (2018) as the process of actively participating in a creative process informed by critical exploration research. For the workshops, Margaret's critical exploration research included looking at painted caribou-skin coats in museums, visiting the coats in person, and reading about them. Listening to stories told by others is another form of critical exploration. Actively participating in a creative process to know more about the research formerly undertaken results in knowing more about the creative practice of making the caribou-skin coats.

Margaret chose not to share her thoughts on the spiritual elements of making the coats, which are unique and private for each person and should not be speculated about. These are her feelings about the physical action of making designs and participating in this project, shared in her project report (Orr 2020):

After seeing painted caribou-skin coats and accessories at the Royal Ontario Museum and at Aanischaaukamikw, I marveled at, and respected, the skill of the artist and the amount of time it must have taken to produce one full coat. Some coats were done very quickly with minimal amount of lines and forms covering the coat. The more detail and more area covered by paint, the longer it takes to make. There were other items of clothing that were made and painted on too. Some were matching sets.

I incorporated personal stories in my designs. In my gun cases (Figure 3) my story is about the water, land, sun, and sky, and energy lines at the tip of the case to ensure a connection to the animal. I kept in mind that the animal presents itself to the hunter and used very bright colors in my designs to be sure they know they are being honoured by these creations.

\section{Research Creation Outcomes}

The direct community participation in project activities means that we cannot measure the longer term impacts of the project, other than to say that they are immeasurable.

Natasia Mukash (2018) speaks of how she approached the research process, as an artist and designer:

For us, the Cree our spirituality comes from surviving off the land, which we still practice today... The Elders I spoke to went directly into their Ancestral knowledge of their parents and grandparents about the traditional ways prior to contact with Europeans. They did not need a book to confirm these teachings or memories. Their gentle teachings about bringing back the knowledge of painting on hides,

\footnotetext{
${ }^{10}$ The first week was a research and creation week in Ouje-Bougoumou, followed by the trip to Toronto.

${ }^{11}$ This can also be described in the way "blood memory" is used to reference the connection to our land. See Monique Mojica, "Stories from the Body: Blood Memory and Organic Texts," in Native American Performance and Representation, edited by S. E. Wilmer (University of Arizona Press, 2009).
} 


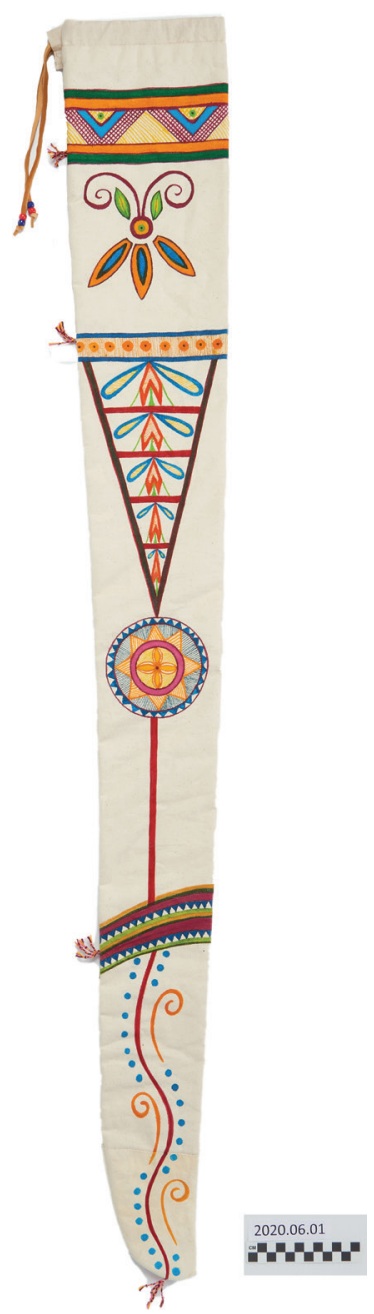

Figure 3: Canvas gun case [2020.06.01] made by Margaret Orr, inspired by painted caribou coats, 2020. Photo by Peter Olson.

which we still practice today but in more contemporary forms that are still very much alive. . . Our designs differ from family to family and person/artist. This allowed me to see the connection between artists today and artists of the past....

Our cultural identity has not been forgotten but has remained visible in the clothes and accessories we use every day ... some information and teachings must only be accessible within our people's knowledge, this is most certainly for the Cree, by the Cree. Some knowledge about sacred and ceremonial parts of our culture must be kept for only some community members to know.

The physical creations from our project (see Figures 4, 5, and 6 for a selection), some of which were added to our permanent collections, as indicated by their object numbers below, include:

- Caribou hides fixed white, prepared by Katrina Orr of Nemaska, Frances George of Whapmagoostui, and Elders from Mistissini, one of which we added to our permanent collection for display purposes [2019.15.01]

- A historic painted caribou coat [2019.07.01]

- Antler and bone painting tools made by Gordon Shecapio Blacksmith of Ouje-Bougoumou [2019.16.01-.08]

- Hide scraps with painted demonstrations using the tools by Natasia Mukash [2019.17.01-.02]

- Artworks by Tim Whiskeychan [2019.02.01-04; 2019.03.01-.86] 


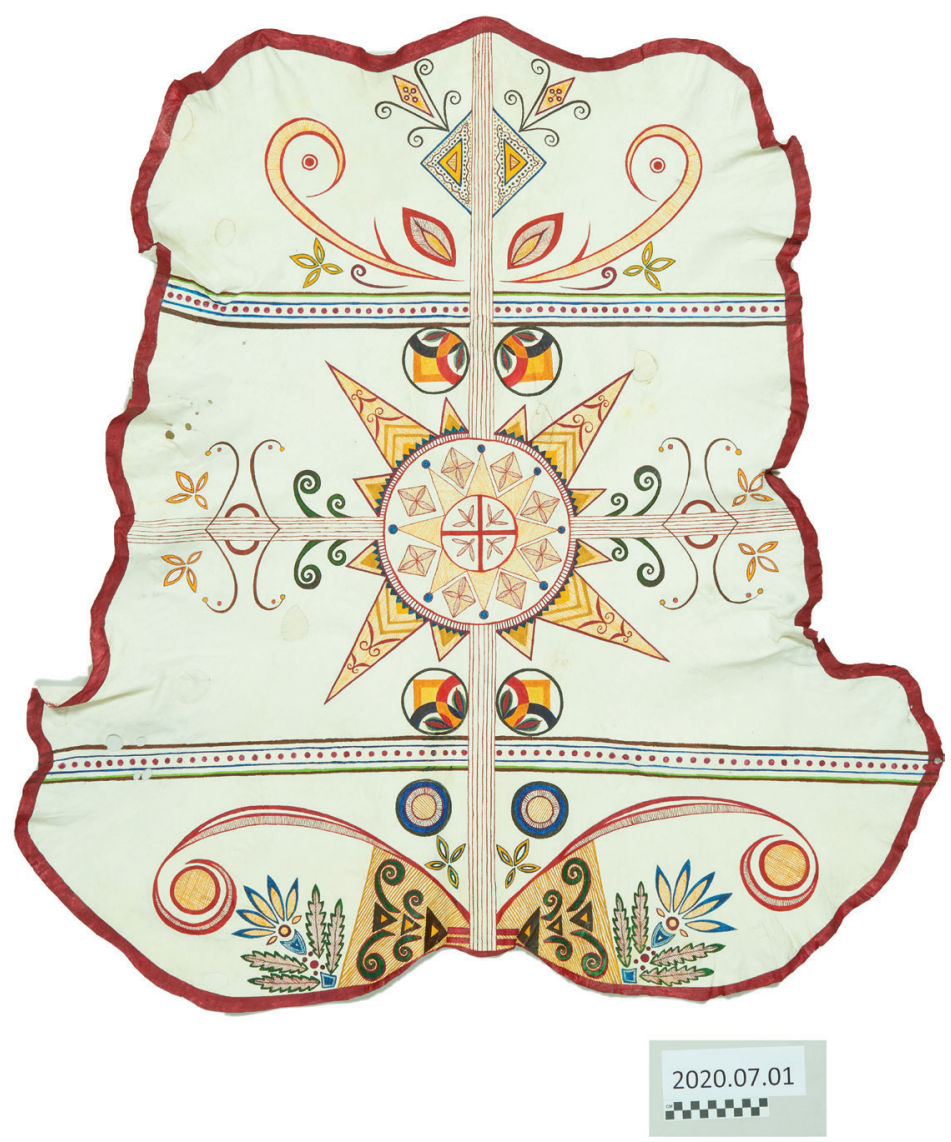

Figure 4: A contemporary painted hide [2020.07.01] by Margaret Orr, Paula Menarick, Cree-Lynn Shecapio, and Emily Sam. Photo by Peter Olson.

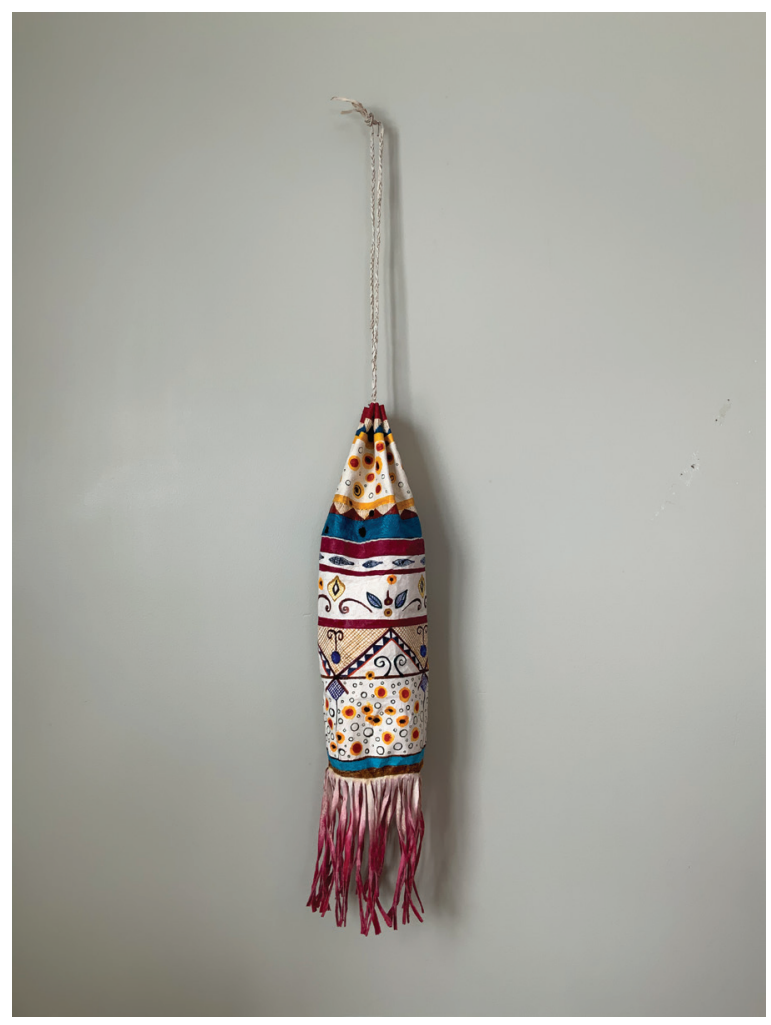

Figure 5: Bag made by Margaret Orr during the project workshops, which she gave to someone as a gift. Photo by Margaret Orr. 


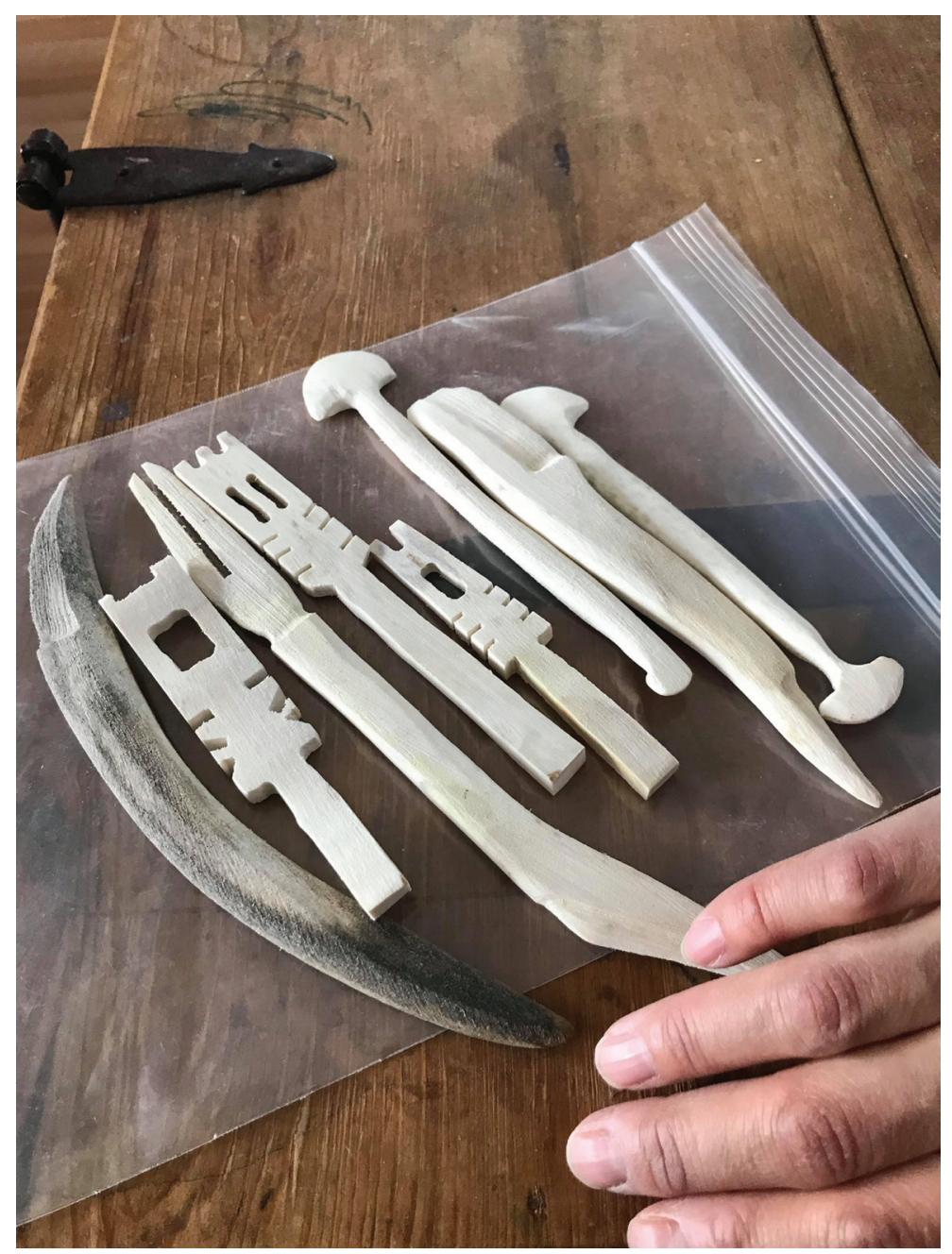

Figure 6: Tools carved from bone and antler [2019.16.01 - .08] by Gordon Shecapio Blacksmith. Photo by Natasia Mukash.

- Artworks by Margaret Orr [2019.13.01 ab; 2019.13.02]

- Artworks by Natasia Mukash in her Caribou Universe series, Past / Future and Reflection [2020.05.01-.02]

- A contemporary painted hide [2020.07.01] by Margaret Orr, Paula Menarick, Cree-Lynn Shecapio, and Emily Sam

- A canvas gun case painted in the style of the ceremonial outfits by Margaret Orr [2020.06.01]

- Painted moose hide child's-sized mittens by Margaret Orr [2020.06.02 ab]

The above list does not include the many creations by community members who participated directly in our workshops, or who carried these teachings into their own artistic process.

In conclusion, we hope that what we have outlined here shows how we have applied Eeyou values and worldview to this project, which was initiated to meet some of the core programming goals formulated as part of the concepts that drove the foundation of Aanischaaukamikw Cree Cultural Institute. Through our community-based research, we connected contemporary Eeyouch to the painted caribou belongings of our ancestors in museums far from our region and demonstrated that it is possible to recognize many familiar elements despite these items being absent for many generations.

\section{References}

Bishop, John E., and Kevin Brousseau. 2018. "I Speak Cree, Not Innu: Ethnically United, Ethnonymically Divided?" In Engaging with Diversity: Multidisciplinary Reflections on Plurality from Quebec, edited by Stéphan Gervais, Raffaele Iacovino, and Mary-Anne Poutanen, 159-83. Brussels; New York: Peter Lang. https://doi.org/10.3726/b14368. 
Candy, Linda, and Ernest Edmonds. 2018. "Practice-Based Research in the Creative Arts: Foundations and Futures from the Front Line." Leonardo 51 (1): 63-69. https://www.muse.jhu.edu/article/686137.

Cole, Peter. 2002. "aboriginalizing methodology: considering the canoe." Qualitative Studies in Education 15 (4): 447-59. https://doi.org/10.1080/09518390210145516.

Coulthard, Glen Sean. 2014. Red Skin, White Masks: Rejecting the Colonial Politics of Recognition. Minneapolis, MN: University of Minnesota Press. https://doi.org/10.5749/minnesota/9780816679645.001.0001.

First Nations Information Governance Centre. 2021. "The First Nations Principles of OCAP®." https://fnigc. ca/ocap-training/. Archived at: https://perma.cc/G3CT-BS7T.

Mailhot, José. 1986. "Beyond Everyone's Horizon Stand the Naskapi." Ethnohistory 33 (4): 384-418. https:// www.doi.org/10.2307/482040.

Manuel, George, and Michael Posluns. (1974) 2019. The Fourth World: An Indian Reality. Minneapolis, MN: University of Minnesota Press. https://doi.org/10.5749/j.ctvf34hsb.

Masty, Emily, and Susan Marshall, eds. 2013. Mind's Eye: Stories from Whapmagoostui. Storytellers Sam Atchynia, Nellie Atchynia, Frankie Dick, Matthew George, Rupert George, John Kawapit, Suzanne Kawapit, William Kawapit, Noah Mamianskum, Ann Masty, Sam Masty, Samson Masty, Hannah Natachequan, Andrew Natachequan, Philip Natachequan, Joseph Rupert, Maggie Sandy, Peter Sandy, Robbie Sheshamush. Ouje Bougoumou: Aanischaaukamikw Cree Cultural Institute.

Menarick, Paula. 2019. Unpublished Research Report: Painted Caribou Coats Project. Ouje Bougoumou: Aanischaaukamikw Cree Cultural Institute.

Mojica, Monique. 2009. "Stories from the Body: Blood Memory and Organic Texts." In Native American Performance and Representation, edited by S. E. Wilmer, 97-109. Tucson, AZ: University of Arizona Press.

Mukash, Natasia. 2018. Unpublished Research Report: Painted Caribou Coats Project. Ouje Bougoumou: Aanischaaukamikw Cree Cultural Institute.

Office of the United Nations High Commissioner for Human Rights. 2007. "Declaration on the Rights of Indigenous Peoples." http://www.ohchr.org/EN/Issues/IPeoples/Pages/Declaration.aspx. Archived at: https://perma.cc/7V6V-MTBS.

Orr, Margaret. 2020. Unpublished Research Report: Painted Caribou Coats Project. Ouje Bougoumou: Aanischaaukamikw Cree Cultural Institute.

Robinson, Dylan. 2020. Hungry Listening: Resonant Theory for Indigenous Sound Studies. Minneapolis, MN: University of Minnesota Press.

Wikipedia. 2020. "Eeyou Istchee (territory)." https://en.wikipedia.org/wiki/Eeyou_Istchee_(territory).

How to cite this article: Aanischaaukamikw Cree Cultural Institute et al. 2021. Rediscovering the Tradition of Painted Caribou Belongings in Eeyou Istchee: A Community-Based and Community-Led Research Project. KULA: Knowledge Creation, Dissemination, and Preservation Studies 5(1). https://doi.org/10.18357/kula.132

Submitted: 06 May 2020 Accepted: 29 January 2021 Published: 22 June 2021

Copyright: @ 2021 The Author(s). This is an open-access article distributed under the terms of the Creative Commons Attribution 4.0 International License (CC-BY 4.0), which permits unrestricted use, distribution, and reproduction in any medium, provided the original author and source are credited. See http:// creativecommons.org/licenses/by/4.0/. 